\title{
O CAOS NO ATENDIMENTO DO SISTEMA ÚNICO DE SAÚDE
}

\author{
THE CHAOS IN THE CARE OF THE UNIFIED HEALTH SYSTEM
}

\author{
TCBC Edmundo Machado Ferraz \\ Presidente do Colégio Brasileiro de Cirurgiões
}

O Brasil é um país privilegiado em muitos aspectos. Conquistamos uma dimensão continental pródiga de recursos naturais que serve para nos rotular de país do futuro. Demonstramos capacidade de resolver inúmeros problemas. Nossa economia cresceu e as oportunidades de desenvolvimento aumentaram, contudo dois problemas públicos não resolvidos entravam nosso projeto de nação: a educação e a saúde. Recente pesquisa nacional de opinião pública revelou que a saúde é considerada o nosso principal problema, maior que a violência urbana.

É importante ressaltar que o problema já é de muitos anos, sendo, portanto, de responsabilidade de muitos e sucessivos governos e também de nós médicos.

Mas vamos iniciar a discussão pelo Governo. Somos um país de 190 milhões de habitantes, 145 milhões usuários do SUS, sistema que completou 20 anos de atividades e teve uma concepção modelar caracterizada pela universalidade e integralidade, porém não foi dotado de recursos orçamentários capazes de fazer cumprir os seus objetivos.

O PIB brasileiro ultrapassou US\$ 1 trilhão de dólares, porém o investimento público em saúde é de apenas 3,5\% do PIB, o que proporciona a aplicação de menos de US\$300,00 dólares por habitante, quantia absolutamente insuficiente para financiar, dentro da concepção como foi idealizado, o sistema público de saúde, bem abaixo do valor mínimo considerado pela Organização Mundial de Saúde (OMS) como mínimo admissível, a quantia de RS\$ 500,00 dólares por habitante. Isto posto, fica evidente que os recursos destinados à saúde são insuficientes nos planos Federal (1,8\% PIB), Estadual e Municipal.

Caracterizado o investimento insuficiente em saúde, isso atinge bem mais do que os 145 milhões de habitantes usuários do SUS. No Brasil, estima-se que apenas 5 a 10 milhões de habitantes utilizam a medicina privada, que pode ser de primeiro mundo para o distinto público que por acaso seja bem informado para selecionar as melhores opções e disponha de recursos para pagar o custo do tratamento.

Os outros 40 milhões de habitantes são usuários de cooperativas e/ou de planos de Previdência privada.

Ocorre que, por falta de regulação adequada do sistema, atribuição do Governo Federal, cerca de metade desses usuários mal informados ou adeptos da "Lei do Gerson" de levar vantagens em tudo, escolheram o plano de saúde pelo menor preço, por desinformação ou falta de alternativa, sem se aperceberem de que não fazem jus a uma série de necessidades que irão aflorar na ocasião da necessidade de tratamento, tais como direito a apenas 1 dia de Unidade de Terapia Intensiva, não-cobertura a operações e procedimentos de alta complexidade. Resumo da ópera: esses pacientes pensam que possuem cobertura de convênio e descobrem, quando precisam, de que não a possuem. E, então, procuram o SUS, onerando e encarecendo ainda mais um Sistema que não foi dotado de fonte adequada de financiamento. Como conseqüência maior, os Hospitais públicos tornam-se superlotados, com filas intermináveis para atendimento, provocando enorme tumulto e desgaste extensivo a todos os usuários e funcionários do Sistema Público de Saúde.

A situação é catastrófica nas grandes cidades e pior ainda na periferia, que se limita a transportar os pacientes, a maioria com problemas banais, para os grandes centros, tumultuando mais ainda o atendimento, aumentando a desorganização do Sistema.

Os Hospitais públicos, com raras e honrosas exceções, que declinaremos adiante, não possuem orçamento, financiando os seus gastos com recursos oriundos do SUS, absolutamente defasados e irreais (tipo $\mathrm{R} \$ 6,62$ reais por uma consulta, $\mathrm{R} \$ 3,00$ por curativo e $\mathrm{R} \$ 363,31$ por uma diária de UTI) o que faz com que qualquer percentual de aumento das tarifas do SUS trombeteado pelos jornais $(20-30 \%$ sobre o valor atual) seja absolutamente insignificante.

Os Hospitais públicos estão degradados apresentando piso arrancado, tetos infiltrados, sistema elétrico e de refrigeração com defeitos, sem manutenção preventiva, equipamentos obsoletos, em número reduzido e sem manutenção, farmácia desabastecida, almoxarifados vazios, lavanderias obsoletas, esterilização sem manutenção ou atualização de equipamentos constituindo tudo isso uma absoluta receita do caos vivido pela quase totalidade das unidades das redes públicas, federal, estadual e municipal.

As exceções são os hospitais públicos dotados de orçamento e mantidos pela Universidade de São Paulo (USP) e pelo Estado de São Paulo particularmente os dotados de novo modelo de Gestão e o Hospital das Clínicas de Porto Alegre, que constitui uma exceção entre os Hospitais de ensino filiados ao MEC.

Esse é o cenário da medicina pública do Brasil, com filas de espera intermináveis, muitas vezes superiores há um ano para tratamento cirúrgico de qualquer doença, estando comprometidas os atos cirúrgicos de alta complexidade por absoluta falta de condições de atendimento e de equipamentos, medicamentos essenciais e disponibilidade de leitos de terapia intensiva para suporte a pacientes graves.

Estima-se que em um período máximo de um ano a grande maioria dos hospitais públicos brasileiros esteja em regime falimentar, incapacitados de cumprirem suas obrigações com nossa população desassistida.

E qual seria a responsabilidade de nós médicos neste processo? 
Apesar da melhoria ocorrida em várias facetas da vida nacional, é indiscutível a piora inexorável da qualidade do atendimento médico em todo o território nacional.

O trabalho médico mal remunerado, cada vez mais realizado em condições precárias de exercício profissional, a necessidade de manter o processo de educação continuada dificultado pelo rápido desenvolvimento tecnológico e acúmulo de novas informações que complicam e encarecem o exercício profissional do médico e nem sempre é bem compreendido pela população.

Assim, o médico e outros profissionais de saúde possuem o "privilégio" do duplo emprego e de uma remuneração indigna, que induz o leigo a imaginar que aquela remuneração deveria ser multiplicada por dois (devido ao duplo emprego) e ainda embutida mais uma outra fonte de remuneração proveniente do consultório, além de outros eventuais "bicos" privados que constituem exceção e não regra.

Ledo engano.

A maioria dos médicos não consegue o duplo emprego. A enorme maioria não tem consultório ou faz uma "ponta" de atendimento em consultório alheio, tipo 1 hora por semana, para não atender ninguém.

A realidade salarial do médico é muito diferente. $\mathrm{Na}$ sua maioria é oriunda de Secretaria Estadual ou Municipal de Saúde e não de cargo de médico do Legislativo ou do Judiciário, que ganha melhor, mas que representa menos da metade do que ganham os seus respectivos patrões, todos pagos por nós contribuintes.

Os salários dos médicos da rede pública situam-se entre $\mathrm{R} \$ 1.200,00$ a $\mathrm{R} \$ 1.800,00$ por carga horária de 20 horas semanais. Considerando a teoria do duplo emprego seria uma renda entre $\mathrm{R} \$ 2.400,00$ e $\mathrm{R} \$ 3.600,00$ por 40 horas semanais, realidade atual do médico brasileiro, situada dentro da faixa do que se considera classe média (até $\mathrm{R} \$ 4.100,00$ ).

Bem diferente, por exemplo, do cargo recém criado, de carcereiro da Polícia Federal, aprovado recentemente pelo Congresso Nacional com salário inicial de R \$ 12.000,00 no mesmo dia em que a Associação Médica Brasileira (AMB) fazia uma ruidosa e concorrida manifestação no Congresso Nacional para solicitar um salário de médico do Serviço Público de R \$7.500,00 para um regime de 20 horas semanais e de $\mathrm{R} \$ 15.000,00$ para 40 horas. O salário de carcereiro foi aprovado sem problemas e a proposta da $\mathrm{AMB}$ ainda não foi votada em plenário.
Não existe medicina privada no Brasil, exceto para cerca de 5\% da população. A realidade é que mais de 145 milhões de brasileiros dependem unicamente do SUS para tratamento de sua saúde.

Podemos concluir claramente que o duplo emprego médico é uma falácia, só prejudica o médico, que ainda é erroneamente rotulado como "vilão" da grande tragédia do mau atendimento prestado à população. Contudo, é preciso reconhecer que precisamos de trabalhar em um sistema onde possamos ser avaliados em presença, eficiência e qualidade de atendimento.

Médico e Educador são profissionais de carreira de Estado, concebida como tal, contratados em cargo único, em regime de CLT, em horário integral, com salário digno, horário que possa ser ajustado entre plantão e/ou complementação ou horário diário contínuo e sem o pretenso "guarda chuva" do funcionário público efetivo protegido por uma estabilidade que muito beneficia os que nada fazem.

E o valor do salário?

O salário é o que a AMB preconiza e que pode ser negociado através de um plano de cargos e salários para que possa ser atingido de acordo com entendimento mútuo.

Greve de médico é inadmissível no Serviço Público, mas não a luta pela dignidade no trabalho e condições adequadas de atendimento do usuário do SUS. A vida não tem preço, mas a medicina tem custo e o governo precisa arcar com sua responsabilidade. A população não pode pagar o preço de não possuir outra alternativa de tratamento.

O diálogo, portanto, precisa ser estabelecido. Não devemos temer a discussão. $\mathrm{O}$ atendimento médico não pode ser improvisado. Necessita de planejamento e execução profissional e novos modelos de gestão para que possa atingir o seu objetivo, que é a melhoria do atendimento de saúde de nossa sofrida população, que nada tem a ver com essa discussão entre médicos, que lutam pela restauração de sua dignidade e condições mínimas adequadas de atendimento, e os governos atuais, que herdaram de um passado distante o produto do descaso acumulado por sucessivas administrações de todos os partidos que se sucederam no poder, colaborando para a construção dessa antiética engenharia do caos. O diálogo é, portanto, irrecusável e inadiável. 